\title{
An Algorithm for the Best Way Connection among Cell-Phone Towers
} Using Feedforward Neural Network

\section{Kais I. Ibraheem Thamir Abdul Hafed Jarjis Yahya Q. Ibrahim}

College of Education

Received on: 06/05/2009

University of Mosul, Iraq

\section{ABSTRACT}

A new approach for mobile radio towers is presented in this paper. The use of feed-forward artificial neural network makes it possible to overcome some important disadvantages of previous random distribution of the towers.

Our sample implementation is based upon the coordinates of a virtual cell phone towers distributed in Mosul city. The results show that the proposed algorithm is sufficiently accurate for use in planning mobile towers distribution system.

Keywords: Artificial Neural network, Mobile radio towers.

$$
\begin{aligned}
& \text { خوارزمية لأفضل وسيلة اتصال بين أبراج الهواتف المحمولة باستخدام الثبكة العصبية ذات التغذية } \\
& \text { الامامية }
\end{aligned}
$$

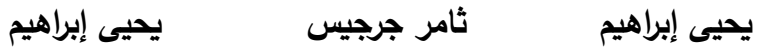

$$
\begin{aligned}
& \text { كلية التربية، جامعة الموصل جايل } \\
& \text { تاريخ القبول: 2009/10/04 } \\
& \text { تاريخ الاستلام: 2009/05/06 - (206 }
\end{aligned}
$$

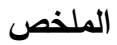

$$
\begin{aligned}
& \text { يتاول هذا البحث نهج جديد لطريقة توزيع أبراج الهاتف المحمول. وتم استخدام الثبكة العصبية } \\
& \text { الاصطناعية ذات التغذية الأمامية التي جعلت من الممكن التغلب على بعض العيوب السابقة والتي تتمثل } \\
& \text { بالتوزيع العشوائي للأبراج } \\
& \text { تم تطبيق الخوارزمية المقترحة على عينة من إحداثيات أبراج الهاتف المحمول الافتراضية الموزعة }
\end{aligned}
$$

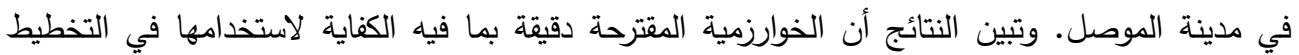

$$
\begin{aligned}
& \text { لنظام توزيع أبراج الهاتف المحمول. } \\
& \text { الكلمات المفتاحية: الشبكة العصبية الاصطناعية، توزيع أبراج الهاتف المحمول. }
\end{aligned}
$$

\section{Introduction:}

Artificial Neural Networks (ANN) are very powerful algorithms that may be used to construct empirical computer models of non-linear physical phenomena. These algorithms successfully operate with large volumes of noisy data [8]. ANN are used in solar-terrestrial physics very efficiently.

Self-Organizing Maps (SOM) are applied for classification of data to distinguish independent processes in complex dynamics of physical systems [13].

The prognoses in time-series of geomagnetic indexes (Dst, Kp, AP,etc.) are generated using Elman Recurrent Neural Networks (ERNN) 
[14]. Multi Layer Perceptrons (MLP) $[9,10]$ or General Regression Neural Network (GRNN), [4] are used to develop complex multi-parameter models in the solar wind magnetosphere coupling system. Group Method of Data Handling (GMDH) [5] presents ANN models in analytical form. Dmitriev el.al. 1999 [3] overview of ANN applications for the development of expert system for modeling and prediction of the space radiation environment firstly the fluxes of high energy electrons and protons that strongly affect the near Earth satellite's operation. They used in there work the software ANN package [11].

According to our concern, the problem that appear in Mosul city is that, the randomly distribution of mobile towers. Such that, when a connection is needed between two regions, the connection pass through many towers depending upon the bandwidth available in each tower. Therefore, the proposal algorithm will find the best way connection among the towers.

\section{Feed Foreword Neural Network:}

The ANN model shown in figure 1, is based on the principles of feedforward neural networks. Feedforward neural networks with sigmoidal activation functions have shown very good performance in solving problems with mild nonlinearity on the set of noisy data [2] (as the data distribution of the coordinates of cell-phones towers). Therefore, that case is fully corresponds to the problem. A key feature of the neural network is the intrinsic parallelism allowing for fast evaluation of solutions.

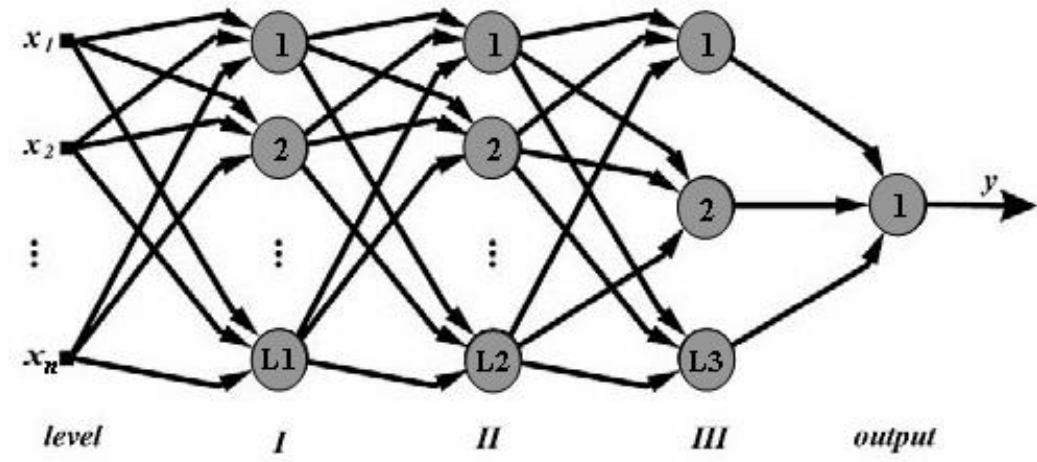

Figure (1) Architecture of the feedforward neural network.

\section{Advantages of Using Artificial Neural Networks:}

NNs have many advantages over conventional methods of analysis. First, they have the ability to analyze complex patterns quickly and with a high degree of accuracy. Second, artificial neural networks make no 
assumptions about the nature of the distribution of the data. They are not biased in their analysis. Instead of making assumptions about the population, NNs with at least one middle layer use the data to develop an internal representation of the relationship between the variables. Better results can be expected with neural networks when the relationship between the variables does not fit an assumed model. Third, since time-series data are dynamic in nature, it is necessary to have non-linear tools in order to discern 25 relationships among time-series. NNs are best at discovering these types of relationships. Fourth, neural networks perform well with missing or incomplete data. Whereas traditional regression analysis is not adaptive, indiscriminately processing older data together with new data, NNs readjust their weights as new input data becomes available [7].

\section{Capacity and Coverage Calculations:}

The capacity of a Code Division Multiple Access (CDMA) cell depends on many different factors, such as power control accuracy, interference power. In this present study we are considering perfect power control. We begin by calculating the signal-to-noise (interference) power $[13,10]$. If there are $\mathrm{N}$ users in a cell and the signal is denoted by $\mathrm{S}$ then the interference can be calculated as $\mathrm{I}=(\mathrm{N}-1) \mathrm{S}+\eta$, where $\eta$ is the back ground thermal noise. Hence the SNR is given by

$$
S N R=\frac{S}{(N-1) S+\eta}=\frac{1}{(N-1)+\eta / S}
$$

Suppose the digital demodulator for each users can operate against the noise at an energy per bit-to noise power density level is given by $\mathrm{Eb} / \mathrm{N} 0$, whose numerator is obtained by dividing the desired signal power by the information bit rate, $\mathrm{R}$, and dividing the noise (or interference) by the total bandwidth, $\mathrm{W}$. This result is

$\frac{E_{b}}{N_{0}}=\frac{W / R}{(N-1)+\eta / S}$

where W/R is generally referred to as the "Processing gain" and the back ground noise determines the cell radius for a given transmitter power. The above equation can be written as the capacity in terms of number of users,

$$
N=1+\frac{W / R}{E_{b} / N_{0}}-\frac{\eta}{S}
$$

That means, the number of users is reduced by the inverse of the per user signal-to-noise ratio (SNR) in the total system spread bandwidth, W. However, if the user is not speaking during part of the conversation, the output of the coder is lowered to prevent the power from being transmitted unnecessarily. This reduces the average of signal power of all users and consequently the interference received by each user. 
The capacity is then increased proportional to this overall rate reduction, provide. In order to attain an increase in capacity, the interference due to other users should be reduced. This can be done using antenna sectorization and monitoring of voice activity [10]. Thus with sectorization and voice activity monitoring factor $\eta$, the average $E_{b} / N_{0}$ is:

$\frac{E_{b}}{N_{0}}=\frac{W / R}{\left(N_{S}-1\right) \alpha+\eta / S}$

Where $\mathrm{N}_{\mathrm{s}}$, the number of users per sector and the interference to be that received by one sector's antenna. Now, consider interference from the jth user in neighbouring cell $\mathrm{k}$, then the ratio of other cell interference to the received signal strength at home base station is I/S [10]. Then equation (4) becomes:

$\frac{E_{b}}{N_{0}}=\frac{W / R}{\left(N_{S}-1\right) \alpha+(I / S) \alpha+\eta / S}$

Where $(I / S)=\left(r_{m} / r_{0}\right)^{m} \cdot\left(\xi_{0}-\xi_{m}\right), \quad \mathrm{r}_{\mathrm{m}}$ is the random distance to the corresponding home cell base station, $\mathrm{r}_{\mathrm{o}}$ is the distance to the neighbouring cell, $\xi_{0}-\xi_{m}$ represent the shadowing parameter and $\mathrm{m}$ is the path loss exponent [10].

We can also write the above equation as

$$
S=\frac{\eta}{\frac{W / R}{E_{b} / N_{0}}-\left(N_{s}-1\right) \alpha-(I / S) \alpha}
$$

Finally, the received power at the base station from the user1, is given by $S=S_{1}-L_{p}-U$

Where $\mathrm{S} 1$ is the transmission power of the user, Lp is propagation path-loss at distance $d$ from the mobile station to base station and $U$ is the shadow fading losses. From equations (6) and (7) we can build relation among the received power, number of users and the coverage area [12].

\section{Flowchart of the algorithm:}

Let us consider the area which represents the Mosul city divided by the districts. The simulator of the tower distribution in this areas districts can be explain in the flowchart below: 


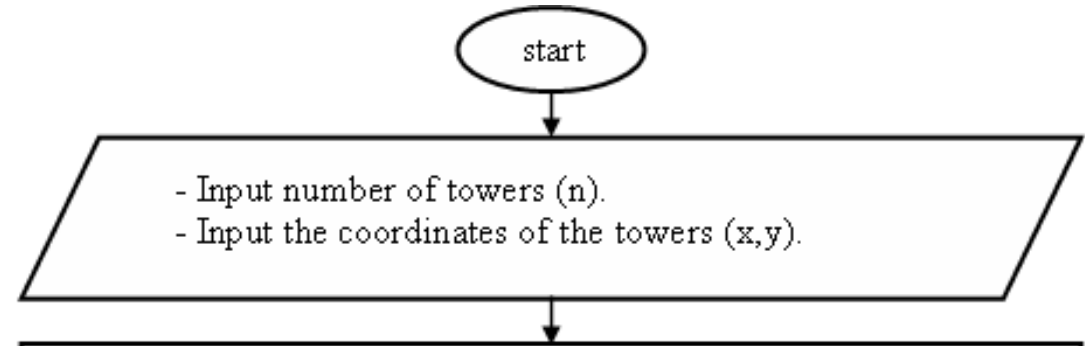

Input basic parameters:

- No. of iteration (maxepoh)

- learning rate, the weight between neurons. $(\theta=0.5)$

- learning rate, the weight between the towers and the neurons.

$(\phi=0.5)$

Count for the distance between every tower with all other towers.

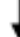

Assign the initial coordinates for every neuron in circular form:

$$
\begin{aligned}
\mathbf{n x}_{\mathrm{i}} & =\mathbf{0 . 5} \cos \left(\alpha_{\mathrm{i}}\right) \\
\mathbf{n y}_{\mathrm{i}} & =0.5 \sin \left(\alpha_{\mathrm{i}}\right) \\
\mathbf{\alpha}_{\mathrm{i}} & =\boldsymbol{\alpha}_{\mathrm{i}-1}+\frac{2 \pi}{\mathrm{n}}
\end{aligned}
$$

Assign the initial weights between the coordinates of all towers for every neurons randomly $[0,1]$. $\left(\mathrm{wx}_{\mathrm{i}}, \mathrm{wy}_{\mathrm{i}}\right)$

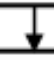

Find the distance between every neuron with other neurons:

$$
D_{i j}=\sqrt{\left(n x_{i}-n x_{j}\right)^{2}+\left(n y_{i}-n_{j}\right)^{2}}
$$

Assign initial weights for every neuron:

$$
\mathbf{I}_{\mathrm{ij}}=\mathbf{e}^{-\frac{n D_{\mathrm{ij}}^{2}}{2 \theta^{2}}}
$$




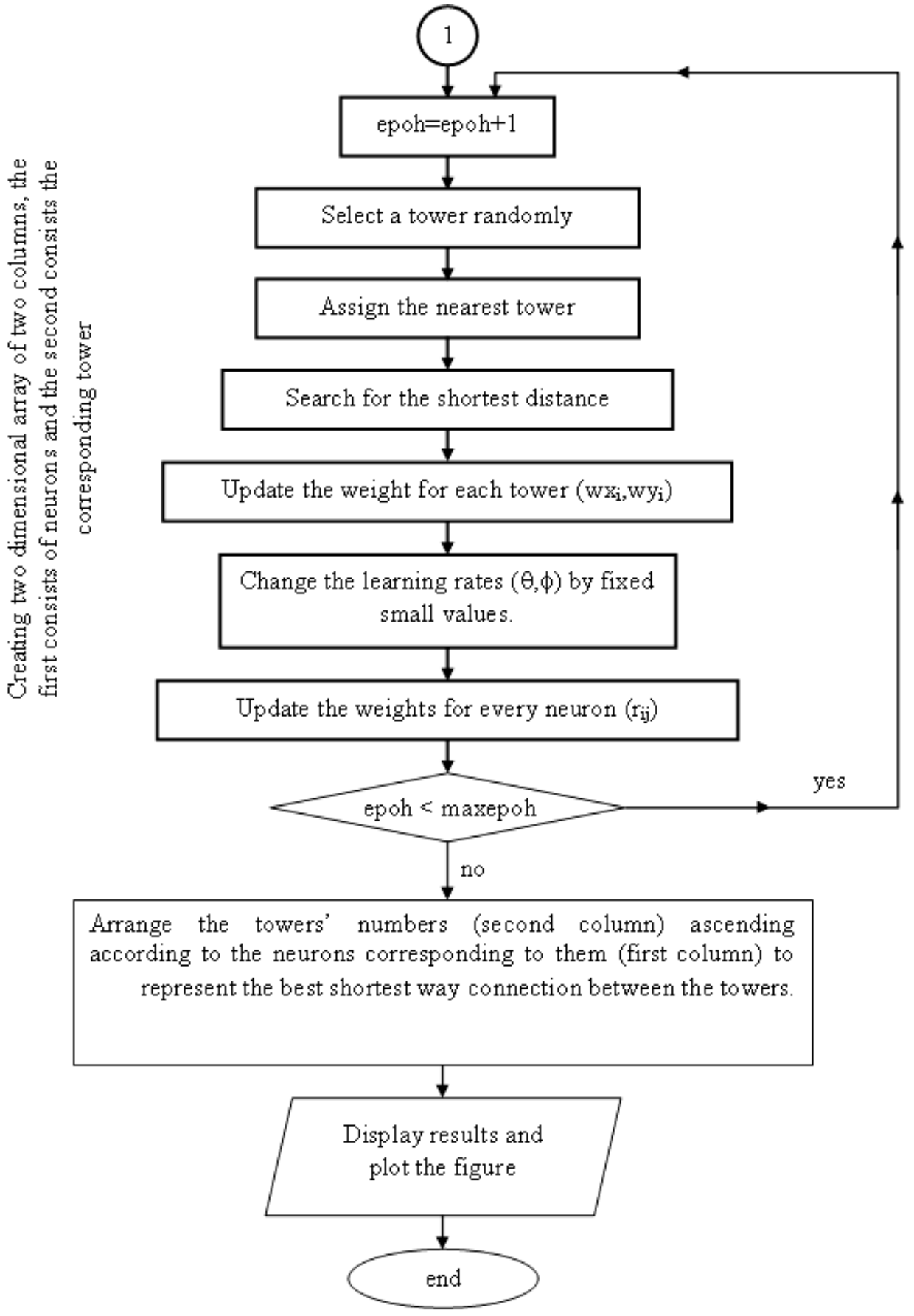




\section{Application of the Algorithm:}

Consider the towers distributions in the 21 areas in the Mosul city shown in figure (2), observe the location of the each tower are shown in table (1), the location of each tower which governed by the coordinates axis of area that is coordinate $\mathrm{v}(\mathrm{x})$ axis and $\mathrm{u}(\mathrm{x})$ axis.

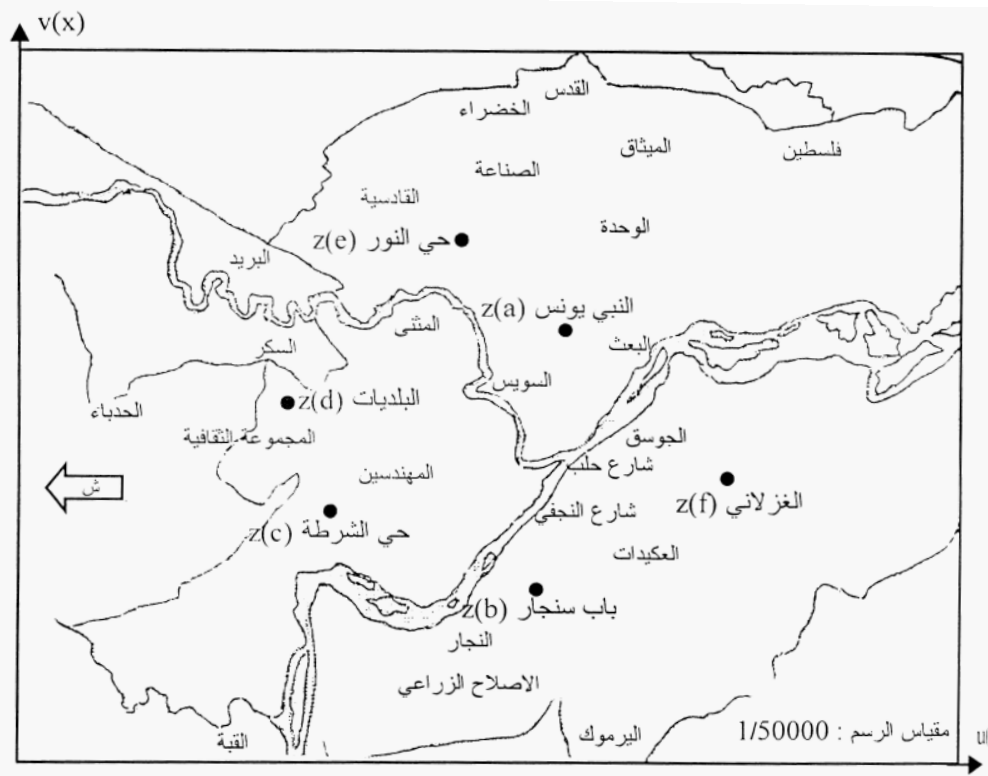

Figure (2) The major districts of the Mosul city [1]

Table (1) the coordinate locations of the each tower [6]

\begin{tabular}{|l|c|c|}
\hline \multicolumn{1}{|c|}{ Areas } & $\mathbf{V ~ ( X )}$ & $\mathbf{U}(\mathbf{X})$ \\
\hline Suais & 8.5 & 11.5 \\
\hline Al-muthana & 10 & 10 \\
\hline Al-muhandisin & 6.5 & 10.5 \\
\hline Halab st. & 6.75 & 13 \\
\hline Al-majmu'ah & 8 & 9 \\
\hline Al-baath & 9 & 14 \\
\hline Al-qadisiyah & 11.5 & 9.5 \\
\hline Al-sukkar & 9.5 & 8 \\
\hline Al-jaosaq & 7 & 15 \\
\hline Al-bareed & 10 & 8 \\
\hline Al-najafi St. & 5 & 13 \\
\hline Al-sina'ah & 12 & 13 \\
\hline Al-'kedat & 5.5 & 14.5 \\
\hline Al-hadbaa & 7.5 & 7 \\
\hline
\end{tabular}




\begin{tabular}{|l|c|c|}
\hline Al-wahda & 12 & 15 \\
\hline Al-najar & 3 & 11.5 \\
\hline Al-khadhraa & 14 & 11.5 \\
\hline Al-mithaq & 14 & 14 \\
\hline Palestine & 12 & 16.5 \\
\hline Al-islah Al-zira'i & 2.5 & 12.5 \\
\hline Al-qudus & 14.5 & 13 \\
\hline Al-yarmuk & 1.5 & 13.5 \\
\hline Al-qubah & 1 & 6 \\
\hline
\end{tabular}

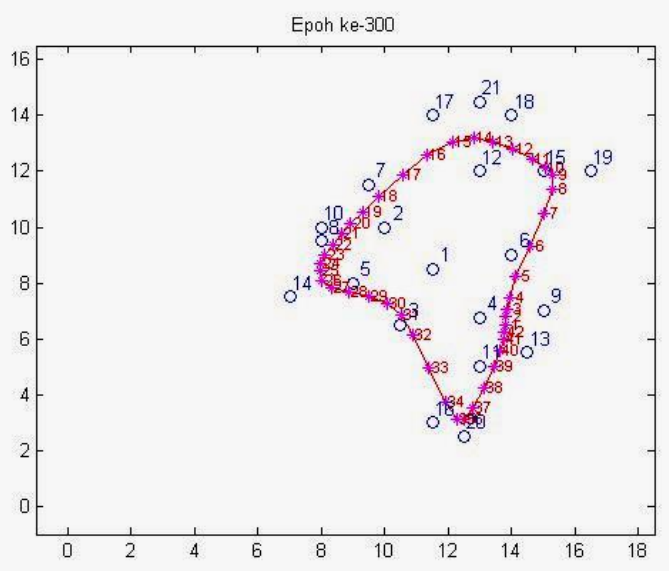

Figure (3) The distribution after iteration 300.

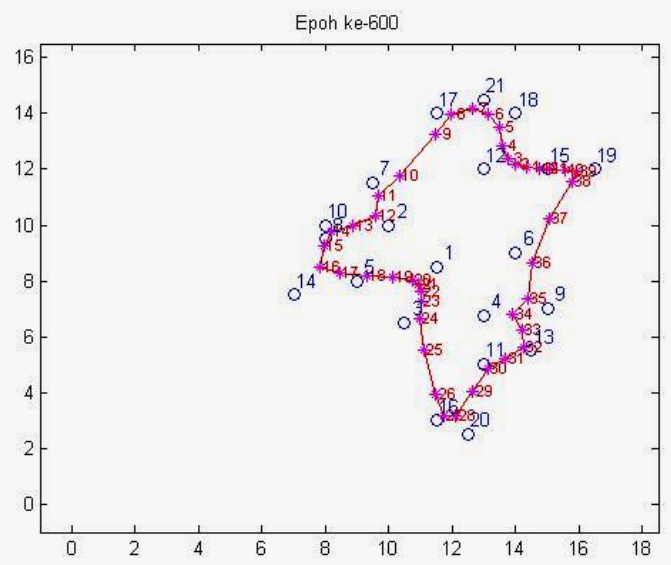

Figure (4) The distribution after iteration 600. 


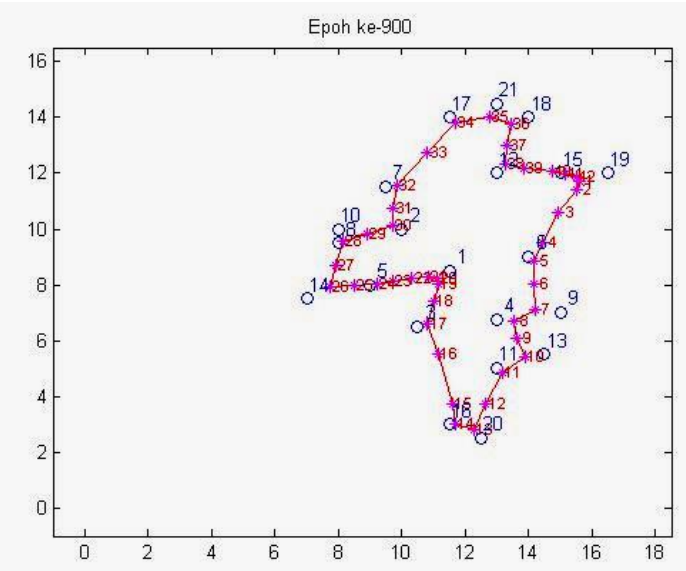

Figure (5) The distribution after iteration 900.

\section{Short way:}

$\begin{array}{lllllllllllllllllllll}4 & 9 & 6 & 19 & 15 & 12 & 18 & 21 & 17 & 7 & 2 & 10 & 8 & 14 & 5 & 1 & 3 & 16 & 20 & 11 & 13\end{array}$

The distribution of the towers above shows the shortest way among the towers, which declares a single path way but indeed the shortest shown in figure 5.

7. Statistics :

\section{Percentage For All Tower Accessing :}

The following table shows the number of access to every tower through the learning process, and the percentage of access of every tower by dividing the number of access for every tower to the total number of access till the neural network ends.

\begin{tabular}{|c|c|c|}
\hline Tower to- & Sum the access & Percentage of accessing \\
\hline 1 & 62 & 5.17 \\
\hline 2 & 40 & 3.33 \\
\hline 3 & 61 & 5.08 \\
\hline 4 & 69 & 5.75 \\
\hline 5 & 62 & 5.17 \\
\hline 6 & 58 & 4.83 \\
\hline 7 & 45 & 3.75 \\
\hline 8 & 58 & 4.83 \\
\hline 9 & 58 & 4.83 \\
\hline 10 & 56 & 4.67 \\
\hline 11 & 53 & 4.42 \\
\hline 12 & 34 & 2.83 \\
\hline 13 & 57 & 4.75 \\
\hline
\end{tabular}




\begin{tabular}{|l|l|l|}
\hline 14 & 75 & 6.25 \\
\hline 15 & 69 & 5.75 \\
\hline 16 & 57 & 4.75 \\
\hline 17 & 65 & 5.42 \\
\hline 18 & 59 & 4.92 \\
\hline 19 & 67 & 5.58 \\
\hline 20 & 55 & 4.58 \\
\hline 21 & 40 & 3.33 \\
\hline
\end{tabular}

Percentage For All Neuron Updated:

\begin{tabular}{|c|c|c|}
\hline Neuron to- & The total update & Percentage of update \\
\hline 1 & 60 & 5.00 \\
\hline 2 & 11 & 0.92 \\
\hline 3 & 6 & 0.50 \\
\hline 4 & 45 & 3.75 \\
\hline 5 & 4 & 0.33 \\
\hline 6 & 51 & 4.25 \\
\hline 7 & 4 & 0.33 \\
\hline 8 & 4 & 0.33 \\
\hline 9 & 76 & 6.33 \\
\hline 10 & 64 & 5.33 \\
\hline 11 & 3 & 0.25 \\
\hline 12 & 25 & 2.08 \\
\hline 13 & 64 & 5.33 \\
\hline 14 & 41 & 3.42 \\
\hline 15 & 66 & 5.50 \\
\hline 16 & 2 & 0.17 \\
\hline 17 & 31 & 2.58 \\
\hline 18 & 48 & 4.00 \\
\hline 19 & 6 & 0.50 \\
\hline 20 & 4 & 0.33 \\
\hline 21 & 47 & 3.92 \\
\hline 22 & 18 & 1.50 \\
\hline 23 & 37 & 3.08 \\
\hline 24 & 4 & 0.33 \\
\hline 25 & 9 & 0.75 \\
\hline 26 & 62 & 5.17 \\
\hline 27 & 5 & 0.42 \\
\hline 28 & 60 & 5.00 \\
\hline
\end{tabular}




\begin{tabular}{|l|c|l|}
\hline 29 & 2 & 0.17 \\
\hline 30 & 56 & 4.67 \\
\hline 31 & 12 & 1.00 \\
\hline 32 & 48 & 4.00 \\
\hline 33 & 1 & 0.08 \\
\hline 34 & 1 & 0.08 \\
\hline 35 & 58 & 4.83 \\
\hline 36 & 50 & 4.17 \\
\hline 37 & 3 & 0.25 \\
\hline 38 & 47 & 3.92 \\
\hline 39 & 5 & 0.42 \\
\hline 40 & 49 & 4.08 \\
\hline 41 & 4 & 0.33 \\
\hline 42 & 7 & 0.58 \\
\hline
\end{tabular}

\section{Conclusion:}

We have presented, discussed and applied an ANN model of perfect power control system for mobile communication towers. This model was developed using ANN. The problem that appeared is: how to use the results of ANN calculations to forecast the distribution of mobile towers. Figure (5) shows the final best scheme of mobile tower distribution of Mosul city region.

The experimental data about the city region are used for prediction of the finest distribution. Finally the results are analyzed by the ANN algorithm in order to select the most appropriate way for getting the best connection among the cell-phone towers.

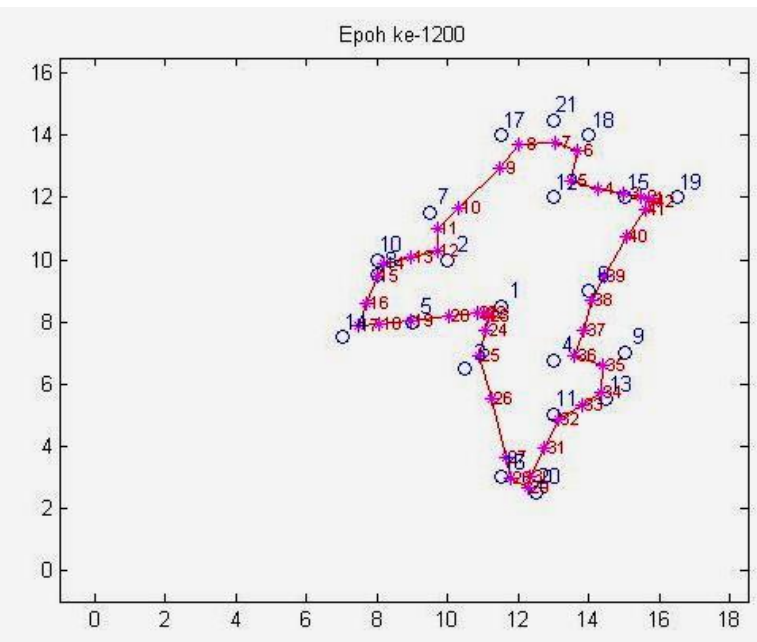

Figure (6) The final best distribution. 


\section{REFERENCES:}

[1] Al-Bayati J. M., Spatial Statistics in Pollution Estimation, thesis, Mathematics dept., College of Edu., University of Mosul, 2004.

[2] D.S. Chen and R.C. Jain, "A robust propagation learning algorithm for function approximation", IEEE Trans. Neural Networks, vol. 5, pp. 467-479, May 1994.

[3] Dmitriev A. Yu. Minaeva, Yu. Orlov, I. Persiantsev, A. Suvorova, I. Veselovsky Artificial Neural Network Applications To The Space Radiation Environment Modelling And Forecasting, SINP MSU, Moscow, Russia, 1999.

[4] Dmitriev A.V. and Yu.V.Orlov, Neuro Shell and multyfactor analysis coupling in the solution of some space physics problems, Abs. of StatPhys-Taipei International Workshop, Taipei, Taiwan, 41, 1997

[5] Dolenko S.A., Yu.V.Orlov, and I.G.Persiantsev, Practical Implementation and Use of Group Method of Data Handling (GMDH): Prospects and Problems, Proc. ACEDC'96, PEDC, University of Plymouth, UK, 291, 1996

[6] Qasim M. I., Al-Bayati J. M., Spatial Statistics in Pollution Estimation, Statis. Sci. J., No.11, V.7, p:54-71, 2007.

[7] Kuo and Reitch, 1994, Pao, 1989; Gilbert, Krishnaswamy, and Pashley, 2000.

[8] Lippman R.P., An Introduction to Computing with Neural Nets, IEEE ASSP Mag., 4, 4, 1987

[9] Liszka L., Modelling of Pseudo-Indeterministic Processes Using Neural Networks, Proc. Int. Workshop on Artificial Intelligence Application in Solar-Terrestrial Physics, Lund, Sweden, 13, 1993

[10] Lundstedt H., Solar Wind Magnetosphere Coupling Processes: Predicted and Modelled with Intelligence Hybrid Systems, Abs. Proc. 1st EGS Alfven Conference on Low-Altitude Investigation of Dayside Magnetospheric Boundary Processes, Kiruna, Sweden, 22, 1996.

[11] NeuroShell 2 User Manual, Fourth edition - June 1996. Ward Systems Group, Inc., Frederick, MD, USA. 
[12] T. Rama Rao and M.V.S.N. Prasad., Coverage and Capacity Studies for a CDMA Cell in Different Radio Propagation Environments, www.ursi.org/Proceedings/ProcGA05/pdf/F04.2(0531).pdf

[13] Wintoft P., and H.Lundstedt, Geomagnetic Activity and Large-Scale Magnetic Field Structures Studed with two Neural Network Paradigms, Proc. Int. Workshop on Artificial Intelligence Application in Solar- Terrestrial Physics, Lund, Sweden, 37, 1993

[14] Wu J-G., and H.Lundstedt, Prediction of Geomagnetic Storms From Solar Wind Data Using Elman Recurrent Neural Networks, Geophys. Res. Letters, 23, 319,1996. 